\title{
Effects of duration of sensory input and intertrial interval on spontaneous alternation in rats with hippocampal lesions*
}

\author{
ROBIN STEVENS $\dagger$ \\ Department of Experimental Psychology, Oxford University, Oxford, England
}

\begin{abstract}
Hippocampectomized rats which were confined for $50 \mathrm{~min}$ in their first chosen arm in a T-maze spontaneously alternated, whereas those confined for $50 \mathrm{sec}$ perseverated choices on the second trial, and a third group which had 50 -sec maze arm exposure followed by 50 -min cage confinement prior to the second trial chose randomly. Intact rats and rats with neocortical lesions behaved identically, spontaneously alternating in all three conditions but with markedly reduced alternation with cage confinement. This experiment corroborated the finding of Kirkby et al (1967), but further shows that it is prolonged exposure to stimuli rather than a longer intertrial interval which produces spontaneous alternation in hippocampectomized rats.
\end{abstract}

Hippocampectomized rats show deficits in spontaneous alternation in a $\mathrm{T}$-maze. Whereas normal animals show a significant tendency to avoid the alley entered on the previous trial, hippocampectomized animals tend to repeat the previous entry (Douglas \& Isaacson, 1964; Kirkby, Stein, Kimble, \& Kimble, 1967; Leaton, 1967; Roberts, Dember, \& Brodwick, 1962). It has been suggested that normal animals show spontaneous alternation because of habituation to the arm most recently entered (Glanzer, 1953; Kivy, Earl, \& Walker, 1956). If so, the alternation deficit in hippocampectomized rats could be through slower habituation, and further, they should be affected in other situations involving habituation. In fact, they continue to explore novel environments when control rats have ceased (Douglas \& Isaacson, 1964; Jarrard \& Bunnell, 1968; Kimble, 1963; Kirkby et al, 1967; Leaton, 1965; Roberts et al, 1962; Sengstake, 1968; Teitelbaum \& Milner, 1963), when exploring a T-maze they make more entries into the arms (Leaton, 1967), and they leverpress at higher rates for a "reward" of a brief flash of light (Kamback, 1967).

Kirkby et al (1967) proposed that hippocampectomized rats were slower at processing information, and therefore in spontaneous alternation tasks the animals will not have satiated to all the stimuli present in the first chosen arm prior to the second trial. They showed that confining hippocampectomized rats in the first chosen arm for $50 \mathrm{sec}$ prior to the second trial produced below-chance levels of alternation, whereas 10 and $50-\mathrm{min}$ confinement periods caused the hippocampectomized rats to alternate on the second trial. However, this prolonged confinement experiment does not conclusively show that the hippocampal

*This work was supported by a research training grant from the Science Research Council, and was submitted to the University of Oxford in partial fulfillment of the requirements for a doctoral degree. I am grateful to Dr. A. Cowey for his help and advice during this experiment.

+Present address: Department of Psychology, The University of Nottingham, University Park, Nottingham, England. spontaneous alternation deficit is a product of a slower rate of information acquisition, as the effects of prolonged exposure to stimuli are confounded with the effects of the time alone. This experiment was performed to determine whether hippocampectomized rats will spontaneously alternate when a long intertrial interval is used, but with the animal retained in a location other than the first chosen side of a T-maze.

\section{METHOD}

\section{Subjects}

The Ss were male Wistar albino rats and male hooded rats. They were obtained and tested over a period of 18 months. All operations were carried out when the animals were approximately 90 days old, and they were tested when they were 110-115 days old. Of the Wistar rats, 17 were given bilateral hippocampal lesions, 24 had neocortical lesions, and 20 were intact. Twenty-five of the hooded rats had hippocampal lesions, 22 had neocortical lesions, and 6 were normal. All animals were naive when tested.

\section{Surgery}

The operations were performed under deep anaesthesia (Equithesin $0.3 \mathrm{ml} / 100 \mathrm{~g}$ ). Multiple bilateral electrode placements were used in making the hippocampal lesions. De Groot (1959) coordinates were used and are given with respect to stereotaxic zero and the surface of the brain: $4.2 \mathrm{~A}$, $1.8 \mathrm{~L}, 2.8 \mathrm{D} ; 2.9 \mathrm{~A}, 2.8 \mathrm{~L}, 3.0 \mathrm{D} ; 2.1 \mathrm{~A}, 5.0 \mathrm{~L}, 4.2 \mathrm{D}$. Radio frequency lesions were made by using a .001-in.-diam tygon-insulated stainless steel wire electrode with a $1-\mathrm{mm}$ exposed tip. Bilateral neocortical lesions were made by aspirating the tissue through a fine-gauge sucker after removing the bone. A narrow strip of neocortex, approximately $7 \mathrm{~mm}$ long $\times 1.5 \mathrm{~mm}$ wide and $2.5 \mathrm{~mm}$ from the midline, was removed. A strip of sterile gelatine foam was placed in the lesion before closing the scalp.

\section{Apparatus}

The Ss were tested in an unpainted plywood T-maze that was $15 \mathrm{~cm}$ wide throughout and had walls $30 \mathrm{~cm}$ deep. A $30-\mathrm{cm}-$ long startbox was separated from the $75-\mathrm{cm}$ stem by a clear Perspex guillotine door. The crosspiece was $90 \mathrm{~cm}$ long, with $30-\mathrm{cm}-\mathrm{long}$ 

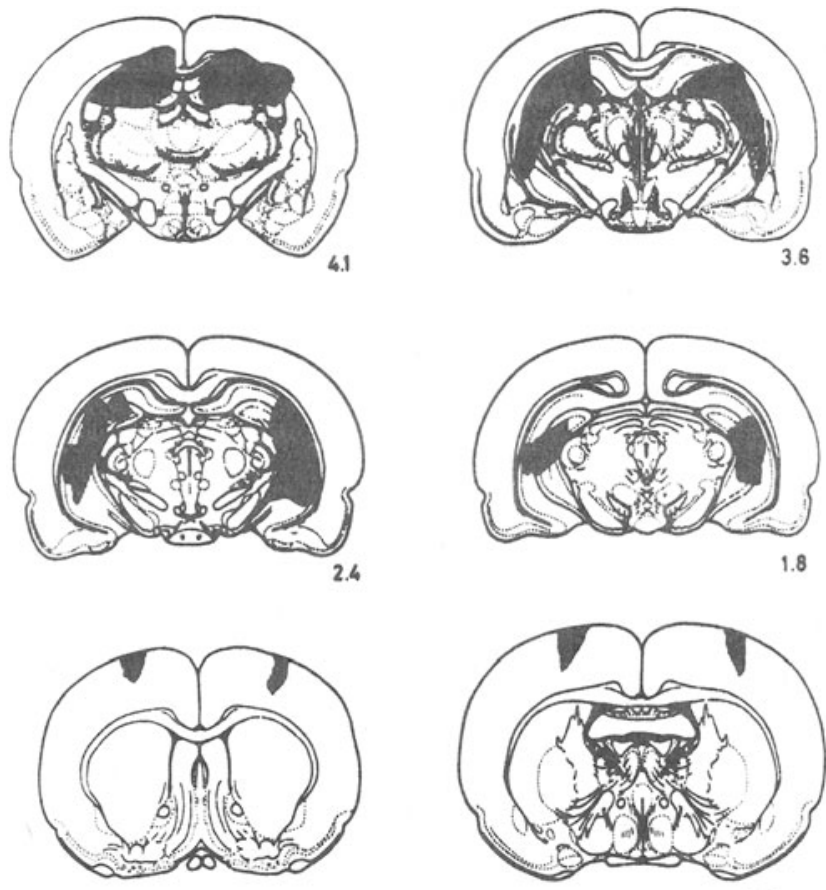

7.9

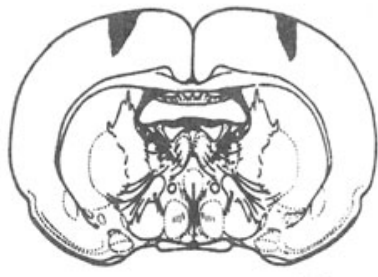

6.0

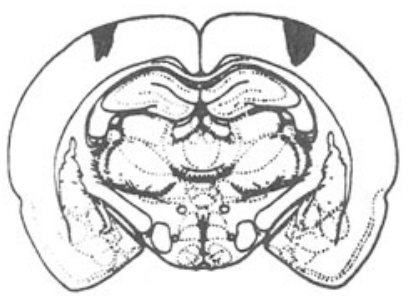

4.1

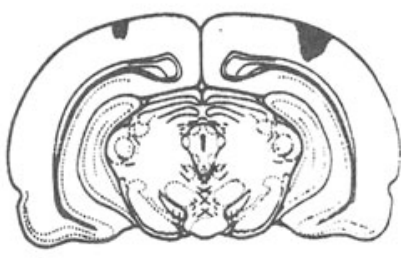

1.8

Fig. 1. Reconstruction of largest (cross hatch) and smallest (black) lesions. Hippocampal lesions are shown in the upper part of the diagram, cortical lesions in the lower.

goalboxes at each end separated from the alley by clear Perspex guillotine doors. The maze was placed on a table in the middle of the testing room, $6 \mathrm{ft}$ below a $100-\mathrm{W}$ light.

\section{Procedure}

There were three test conditions, and animals were allocated to these as follows. Immediate retest Ss were given $50 \mathrm{sec}$ in the first chosen arm, and this was followed immediately by the second trial; there were 18 hippocampals, 18 cortical controls, and 13 normal controls in this condition. Cage-delayed retest Ss were also given $50 \mathrm{sec}$ in their first chosen arm but were then placed in a detention cage for $50 \mathrm{~min}$ prior to the second trial; there were 16 hippocampals, 18 cortical controls, and 13 normal controls in this condition. In the third condition, animals were kept in their first chosen arm for $50 \mathrm{~min}$ and then retested; there were 10 hippocampals and 10 cortical controls in this condition. The animals were maintained on ad lib food and water, but neither was given in the test situation. All Ss were handled and stroked for $5 \mathrm{~min}$ each on the day before testing. Two trials were given in the maze as follows: $5 \mathrm{sec}$ after placing an animal in the startbox, all three guillotine doors were raised and the rat was allowed to enter either arm. As soon as the choice had been made, the doors were lowered and the rat was confined for the appropriate period for his test condition. Cage-delayed Ss were placed in individual detention cages after their $50 \mathrm{sec}$ in the arm. Vicarious trial and error was minimized by preventing retracing if an animal entered a goalbox up to his hindquarters. However, this was infrequently a problem. The second trial followed the same procedure as the first trial. The floor of the maze was wiped with a damp cloth between trials.

\section{Histology}

Following the experiment, the animals were killed with an overdose of Nembutal and perfused through the heart, first with isotonic saline and then with formol-alcohol (10\% formalin in $70 \%$ alcohol). Frozen sections were taken through the lesion area at 50 microns, and every fifth section was stained with thionin. The lesions were reconstructed by tracing the damage onto cyclostyled drawings of sections through the rat brain taken at the appropriate levels from the atlas of König and Klippel (1963). Estimates of the lesion size were made with a planimeter.

The histological findings are summarized in Fig. 1. The hippocampal lesions were estimated to involve $28 \%-83 \%$ of the structure; the median lesion size was $65 \%$. There was damage to corpus callosum, fornix, and fimbria in all the hippocampectomized rats, and in a few animals there was damage to stria terminalis, caudate nucleus, stria medullaris, and lateral thalamic nucleus. Lateral geniculate body damage was found in 10 animals. The lesions in the neocortical controls did not invade the underlying structures, and the posterior aspect only slightly damaged visual cortex.

\section{RESULTS}

As no differences were found between the behavior of the Wistar albino rats and the hooded rats, their results have been combined for statistical testing. Of the rats with hippocampal lesions, 5 out of 18 alternated on the second trial in the 50-sec maze-confinement condition, whereas 8 out of 10 confined for $50 \mathrm{~min}$ in the maze alternated. This difference was significant $\left(\chi^{2}=8.45\right.$, $\mathrm{p}<.01$ ). Seventeen out of 18 cortical controls alternated in the 50-sec maze-confinement condition, and 7 out of 10 alternated in the 50 -min maze-confinement condition. There was no significant difference between the two conditions.

The normal controls and the neocortically lesioned controls were no different in either the immediate retest condition or the cage-delayed condition, so control groups were combined for further statistical testing. Of rats with hippocampal lesions, 7 out of 16 alternated in the cage-confinement condition, and this was not significantly different from the proportions alternating in the immediate retest or maze-delayed conditions. Twenty out of 31 combined controls alternated in the cage-confinement condition, a tendency which was significantly different from that of the combined controls in the 50-sec maze-confinement condition, when 28 out of 31 alternated $\left(\chi^{2}=4.52, p<.05\right)$. The rats with hippocampal lesions alternated significantly less than the combined controls in the 50-sec maze-confinement condition $\left(\chi^{2}=20.16, p<.001\right)$. But in the remaining two conditions, the 
hippocampectomized rats were not significantly different from the controls.

There was no relationship between the size of the hippocampal lesions and perseverative tendencies in any of the three conditions. However, there was a tendency for the size of the hippocampal lesions in the 50-min maze-confinement group to be larger than those of the other two hippocampal groups. Thus, the median lesion size for the hippocampals was $72 \%$ for the $50-\mathrm{min}$ maze-confinement group, $61 \%$ for the $50-\mathrm{sec}$ maze-confinement group, and $64 \%$ for the cage-confinement group. The difference between the 50-min maze-confinement hippocampals and the other two groups combined was not significant (Mann-Whitney $\mathrm{U}=204, \mathrm{p}>.30$ ). There was no clear relationship between extrahippocampal damage and perseverative tendencies, although there was a tendency for there to be more extensive damage to fornix and fimbria in the perseverating hippocampals.

\section{DISCUSSION}

The results confirm the previous experiments on spontaneous alternation in hippocampectomized rats which showed perseveration when intertrial intervals of $1 \mathrm{~min}$ or less were used (Douglas \& Isaacson, 1964; Kirkby et al, 1967; Roberts et al, 1962). Moreover, spontaneous alternation was found in the 50-min maze-confinement hippocampectomized animals, which corroborates the finding of Kirkby et al (1967). The control Ss clearly alternated under the $50-\mathrm{sec}$ and 50-min maze-confinement conditions, and there is a strong likelihood that they alternated in the 50-min cage-confinement condition. The hippocampectomized rats chose randomly on the second trial in this latter condition.

The perseveration of choices by the 50-sec maze-confinement hippocampal group cannot, on the basis of the present experiment, be ascribed to either response perseveration or stimulus perseveration. This question remains to be resolved, although Kirkby et al (1967) found that both intact rats and hippocampectomized rats response perseverated in a cross maze when animals were started from opposite stems on sequential trials. However, on the basis of their experiment, it cannot be determined whether the rats were response perseverating or stimulus alternating, because the maze was painted gray throughout.

Clearly, a long intertrial interval by itself is not sufficient to cause alternation in hippocampectomized rats, but neither did it produce the same pattern of responding as a short intertrial interval. Although the combined controls are not statistically significantly different from the hippocampal rats in the cage-confinement condition, it is apparent that the latter are choosing randomly on their second trial, whereas the controls are tending to alternate. Previous work with intact rats (Walker, 1956; Still, 1966) has shown that the tendency to alternate falls off markedly with increasing intertrial intervals. It is likely that this tendency explains the much reduced alternation found in the cage-confined combined controis. If the long intertrial interval causes forgetting of the first chosen stimulus or response in intact animals-hence their poorer alternation-it may also cause the hippocampectomized rats to forget their initial responses, so causing their second-trial choices to be random.

Long exposure to the stimuli present in the first chosen arm, rather than a long intertrial interval per se, is apparently the critical factor involved in producing alternation in a T-maze in hippocampectomized rats. The explanation for this could be the one proposed by Kirkby et al (1967), that the hippocampectomized rats are slower at processing stimulus information and hence fail to habituate sufficiently to the stimuli present in the maze. Alternatively, the behavior of these animals could be explained in terms of Kimble's (1968) theory of internal inhibition. If internal inhibition in hippocampectomized animals is initially abnormally low and decays rapidly, then their perseverative behavior in the 50-sec maze-confinement condition is expected, but further, the long maze exposure would allow sufficient internal inhibition to be generated to produce alternation.

On the basis of the present experiment and Kirkby et al (1967), it appears that the behavior of hippocampectomized rats in T-maze spontaneous alternation situations is governed by external stimuli rather than internal response initiating and inhibition tendencies. However, Kirkby et al also found that hippocampectomized rats response perseverated (and hence stimulus alternated) in a cross-maze, and similarly, Dalland (1970) found that rats with dorsal hippocampal lesions response perseverated in a cross-maze. In both these cross-maze experiments, the duration of exposure in the first chosen arm was extremely short, $15 \mathrm{sec}$ or less. It is apparent that the factors controlling spontaneous alternation in hippocampectomized rats are complex, and several anomalies in findings remain to be resolved.

\section{REFERENCES}

Dalland, T. Response and stimulus perseveration in rats with septal and dorsal hippocampal lesions. Journal of Comparative \& Physiological Psychology, 1970, 71, 114-118.

De Groot, J. The rat forebrain in stereotaxic co-ordinates. Amsterdam: N.V. Noord-Hollandsche Uitgers Maatschppij, 1959.

Douglas, R. J., \& Isaacson, R. L. Hippocampal lesions and activity. Psychonomic Science, 1964, 1, 187-188.

Glanzer, M. Stimulus satiation: An explanation of spontaneous alternation and related phenomena. Psychological Review, $1953,60,257-268$.

Jarrard, L. E., \& Bunnel, B. N. Open field behavior of hippocampal lesioned rats and hamsters. Journal of Comparative \& Physiological Psychology, 1968, 66, 500-502.

Kamback, M. Effect of hippocampal lesions and food deprivation on response for stimulus change. Journal of 
Comparative \& Physiological Psychology, 1967, 63, 231-235.

Kimble, D. P. The effects of bilateral hippocampal lesions in rats. Journal of Comparative \& Physiological Psychology, 1963, 56, 273-283.

Kimble, D. P. Hippocampus and internal inhibition. Psychological Bulletin, 1968, 70, 285-295.

Kirkby, R. J., Stein, D. G., Kimble, R. J., \& Kimble, D. P. Effects of hippocampal lesions and duration of sensory input on spontaneous alternation. Journal of Comparative \& Physiological Psychology, 1967, 64, 342-345.

Kivy, P. N., Earl, R. W., \& Walker, E. L. Stimulus context and satiation. Journal of Comparative \& Physiological Psychology, 1956, 49, 90-92.

König, J. F. R., \& Klippel, R. A. The rat brain: A stereotaxic atlas of the forebrain and lower parts of the brain stem. Baltimore: Williams \& Wilkins, 1963.

Leaton, R. N. Exploratory behavior in rats with hippocampal lesions. Journal of Comparative \& Physiological Psychology, $1965,59,325-330$.

Leaton, R. N. Patterns of behavior of hippocampal lesioned rats in an exploratory motivated situation. Psychological Reports, $1967,21,153-159$.

Roberts, W. A., Dember, W. N., \& Brodwick, M. Alternation and exploration in rats with hippocampal lesions. Journal of Comparative \& Physiological Psychology, 1962, 55, 695-700.

Sengstake, C. B. Habituation and activity patterns of rats with large hippocampal lesions under various drive conditions. Journal of Comparative \& Physiological Psychology, 1968, 65, 504-506.

Still, A. W. Repetition and alternation in rats. Quarterly Journal of Experimental Psychology, 1966, 18, 103-108.

Teitelbaum, M., \& Milner, P. Activity changes following partial hippocampal lesions in rats. Journal of Comparative \& Physiological Psychology, 1963, 56, 284-289.

Walker, E. L. The duration and course of the reaction decrement and the influence of reward. Journal of Comparative \& Physiological Psychology, 1956, 49, 167-176.

(Received for publication August 28, 1972; revision received October 2,1972 .) 